\author{
DIE FELDZÜGE DES BOLESŁAW SCHIEFMUND \\ NACH BELGARD UND KOLBERG UND DIE ANFÄNGE \\ DER SYMBOLISCHEN INBESITZNAHME POMMERNS \\ DURCH POLEN
}

\title{
THE EXPEDITIONS OF BOLESLAW III WRYMOUTH TO BELGARD (POLISH: BIALOGARD) AND KOLBERG (POLISH: KOLOBRZEG) AND THE BEGINNING OF THE POLISH SYMBOLIC APPROPRIATION OF POMERANIA
}

Keywords: history of Poland, history of Pomerania, Polish medieval chronicles, historical myths, Kołobrzeg / Kolberg, Białogard / Belgard

\section{Summary}

For 150 years Kołobrzeg was an important place of remembrance in Germany. In 1945 Pomerania together with that town was captured by the Polish state after bloody fights of the Polish army. With the reference to the 1945 battle the Polish created several historical myths, which also refer to a Medieval narrative. The article is an attempt to investigate on the basis of chronicles - whether already in the Middle Ages the narrative about Kołobrzeg and nearby Białogard played a similar role in the symbolic policy among the Polish elites. The first part of the article describes the records of chroniclers about the expeditions of Bolesław III Wrymouth to Białogard and Kołobrzeg. The second part

\footnotetext{
* dr Paweł Migdalski, Uniwersytet Szczeciński, Instytut Historii i Stosunków Międzynarodowych, p_r_migdalski@poczta.onet.pl. ORCID: 0000-0002-1988-7225.
} 
depicts their significance against the background of the contemporary political situation. It seems that at the beginning of the 12th century Gallus Anonymus (Anonymous) tried to invest those towns with symbolic significance, but with time chroniclers changed the original meaning of the records and entwined their elements in the current political discourse. Those plots came back only when the idea of the union between Poland and Pomerania re-emerged.

Nach dem Zweiten Weltkrieg, als der polnische Staat nach fast tausend Jahren erneut die Herrschaft über den größten Teil Pommerns übernahm - so die damalige Sprachregelung - wurde die Hafenstadt Kołobrzeg (Kolberg) zu einem wichtigen Erinnerungsort für die neu angekommenen polnischen Bürger. Man erinnerte in der Stadt an wichtige Ereignisse der polnischen Geschichte, wie die Gründung des dem Erzbistum Gnesen unterstellten Bistums im Jahre $1000^{1}$ oder die verschiedenen Kämpfe, die polnische Soldaten um die Stadt geführt hatten: unter Bolesław III. Schiefmund, bei der Belagerung der preußischen Festung im Jahre 1807 unter polnischer Beteiligung, insbesondere aber bei der Einnahme der Stadt durch die Erste Polnische Armee des Polnischen Heeres am 18. März 1945. Diese war mit großen Verlusten verbunden und fand ihren krönenden Abschluss in der Zeremonie der Vermählung Polens mit dem Meer. ${ }^{2}$

1 Den Bericht Thietmars zum Bistum in Kolberg und über die Tätigkeiten des dortigen Bischofs Reinbern untersuchte S. Rosik, „Reinbern - Salse Cholbergiensis aecclesice episcopus“, in: Salsa Cholbergiensis. Kołobrzeg w średniowieczu, hrsg. v. L. Leciejewicz, M. Rębkowski (Kołobrzeg: Le Petit Café, 2000), 85-93. Dank dieser Überlieferung zum Bistum konnte nach 1945 die spätgotische Stiftskirche in Kołobrzeg vor dem Abriss bewahrt werden. Vgl. dazu K. Bastowska, „Polityka władz wobec zabytkowych obiektów sakralnych Pomorza Środkowego w latach 1945-1966 - mity, niedomówienia, półprawdy“, in: Kościót katolicki w realiach władzy komunistycznej na Pomorzu Środkowym w latach 1945-1989, hrsg. v. P. Knap, T. Ceynowa (Szczecin: IPN, 2011), 84, 94, 96.

2 Vgl. etwa den Film Bitwa o Kolobrzeg von Jerzy Bossak aus dem Jahr 1945. Sonderausgabe des Filmmagazins Polska Kronika Filmowa Nr. 9-10/45. Zum Denkmal der Vermählung mit dem Meer und den Feiern anlässlich der Jahrestage der Kämpfe 1945 vgl. Z. Mazur, „Między ratuszem, kościołem i cmentarzem“, in: Wokót niemieckiego dziedzictwa kulturowego na Ziemiach Zachodnich i Pótnocnych, hrsg. v. Z. Mazur (Poznań: Instytut Zachodni, 1997), 322; Z. Romanow, Kreowanie „polityki pamięci” na Pomorzu Zachodnim w latach 1945-2000 (Poznań: Instytut Zachodni, 2002) (Zeszyty Instytutu Zachodniego Nr 24/2002), 22. Zur Bedeutung der Vermählung mit dem Meer für die Propaganda vgl. E. Krasucki, „Zaślubiny z morzem - powojenny mit założycielski Kołobrzegu. Kilka uwag wokół nieco wstydliwej historii“, in: Kolobrzeg i okolice poprzez wieki, hrsg. v. R. Ptaszyński (Szczecin: Kadruk, 2010), 297-319. An die heldenhaften Kämpfe der polnischen Soldaten sollte auch das Festival des Soldatenliedes erinnern, das von 1968 bis 1989 in Kołobrzeg stattfand (vgl. K. Bittner, Piosenka w stużbie propagandy. Festiwal Piosenki Żotnierskiej w Kołobrzegu 1968-1989 (Poznań: IPN, 2015) sowie das Polnische Waffenmuseum und Medienberichte (vgl. M. Prusak, „Obraz walk o Kołobrzeg w 1945 roku w audycjach Radia Koszalin w latach 1953-1989“, 
Neben den Kämpfen, die 1945 stattgefunden hatten, wurden zu Propagandazwecken vor allem Motive benutzt, die mit der Piastenzeit verbunden waren, insbesondere mit den Feldzügen Bolesław Schiefmunds nach Kolberg und Belgard in den Jahren 1102, 1103 und 1107. Der damalige Chronist Gallus Anonymus führt in einem seiner Berichte ein Lied an, das mit den Worten beginnt: „Pisces salsos et fetentes apportabant alii (Salzige und übelriechende Fische holten andere (nämlich die Väter) ${ }^{\text {“3 }}$. Dieses Lied wurde nach den Worten des Krakauer Historikers Józef Mitkowski „zum Lied des Bundes zwischen Polen und der Ostsee“. ${ }^{4}$ Die Geschichtsschreibung wurde nach 1945 in den Legitimationsprozess der polnischen Herrschaft über die Westgebiete eingespannt und griff gerne auf die historischen Kämpfe um Kolberg und die später von Czesław Niemen ${ }^{5}$ wundervoll vertonte „Hymne“ ${ }^{“ 6}$ zurück. Dass Kolberg für die Deutschen nach der Belagerung 1807 oder auch am Ende des Zweiten Weltkrieges ${ }^{7}$ und für die Polen

in: Polifonia pamięci. Między niemiecka przeszłościa a polska teraźniejszościa. Kołobrzeg 19452015, hrsg. v. R. Ptaszyński, J. Suchy (Szczecin: Wydawnictwo Naukowe Wydziału Humanistycznego Uniwersytetu Szczecińskiego MINERWA, 2017), 183-204). Nicht zu vergessen sind in diesem Zusammenhang die Denkmäler (insbesondere das Denkmal zur Vermählung Polens mit dem Meer neben dem Soldatenfriedhof und das Denkmal für die Sanitäterin). Zur Literatur über Kolberg siehe J. Watrak, A. Sawicka, „Die polnische Lyrik nach 1945 über Kotobrzeg (Kolberg). Einige Anmerkungen“, Pommersches Jahrbuch für Literatur 2 (2007): 274 ff. Erwähnenswert ist hier, dass mit dem Akt der Vermählung mit der Ostsee 1945 eine ähnliche Zeremonie aufgegriffen wurde, die General Józef Haller im Februar 1920 in Puck vorgenommen hatte, vgl. H. Kroczyński, Zaślubiny Polski z morzem (Kołobrzeg: Le Petit Café, 1999).

3 Übersetzt nach: W. Schich, Wirtschaft und Kulturlandschaft. Gesammelte Beiträge 1977 bis 1999 zur Geschichte der Zisterzienser und der „Germania Slavica“ (Berlin: BWV - Berliner Wissenschafts-Verlag, 2007), 274.

4 J. Mitkowski, Pomorze Zachodnie w stosunku do Polski (Poznań: Instytut Zachodni, 1946), 46. Es ist zu betonen, dass Wollin bereits im 10. Jahrhundert der zweite Erinnerungsort war, der die Verbindungen zwischen Polen und der Ostsee unterstreichen sollte, vgl. P. Migdalski, „Kreowanie polityki pamięci w Wolinie w okresie kulminacji obchodów Tysiąclecia Państwa Polskiego (1966-1967)“, in: Kulturowe konteksty pamięci Pomorzan. XIII Konferencja Kaszubsko-Pomorska, hrsg. v. C. Obracht-Prądzyński (Słupsk, Gdańsk: Muzeum Pomorza Środkowego w Słupsku, Instytut Kaszubski, 2016), 156-179.

5 Das Lied wurde in einem Film über die Chronik (Kronika polska Galla Anonima) verwendet. Dieser Film wurde 1977 von Grzegorz Królikiewicz gedreht, den Text hat Czesław Niemen vertont. Ein Teil des Liedtextes befindet sich unter anderem auf einer Gedenktafel in der Aleja Żeglarzy in Stettin und an der Bibliothek in Kolberg, die seit 1966 nach Gallus Anonymus benannt ist.

6 Um hier nur einige Autoren zu nennen: L. Gustowski, Polska a Pomorze Odrzańskie (Warszawa: Państwowe Zakłady Wydawnictw Szkolnych, 1946), 16; A. F. Grabski, Bolesław Krzywousty 10851138 (Warszawa: Ministerstwo Obrony Narodowej, 1968), 104-105; B. Dopierała, Polskie losy Pomorza Zachodniego (Poznań: Wydawnictwo Poznańskie, 1970), 37; W. Myślenicki, Piastowski nurt Odry (Poznań: Wydawnictwo Poznańskie, 1972), 243; G. Labuda, Historia Kaszubów w dziejach Pomorza, Bd. I: Czasy średniowieczne (Gdańsk: Instytut Kaszubski, 2006), 93.

7 Vgl. den Film „Kolberg“ von Veit Harlan aus dem Jahr 1945. U. Schröder, „Veit Harlans ,Kolberg‘. Der letzte ,Großfilm‘ der UFA“, in: Konstelacja Szczecin. Aktorzy szczecińscy i kino okresu 
nach $1945^{8}$ zum Erinnerungsort wurde, steht außer Zweifel. Der vorliegende Beitrag möchte jedoch die Chroniken untersuchen und dabei der Frage nachgehen, ob die Geschichtserzählung um Kolberg und das nahe gelegene Belgard nicht bereits im Mittelalter ansatzweise eine ähnliche Rolle in der symbolischen Politik der polnischen Eliten erfüllte.

Beide Orte werden erstmals in der Chronik des Gallus Anonymus erwähnt, die um 1113-1118 entstand. Der Chronist legt in seinem Werk das Programm der polnischen Expansion in Pommern dar, deren Ziel es war, die Herrschaft über die Gebiete an der Ostsee zu erlangen. Zum Schutzpatron dieses Vorhabens beruft Gallus den Heiligen Adalbert, der damals in Polen zunehmend verehrt wurde. ${ }^{9}$ Die Unterstützung des Heiligen sollte der Eroberung Pommerns göttliche Legitimation versichern. ${ }^{10}$ Kurz nach dem Tod Władysław Hermanns im Jahre 1102 machte sich der junge Bolesław Schiefmund auf, um ins Zentrum des heidnischen Gebietes vorzustoßen (meditullium patrie paganorum). Er erreichte die wohlhabende und volkreiche (urbs opulenta et populosa), königliche, hervorragende Stadt namens Alba (urbs regia et egregia Albam nomine). Man geht davon aus, dass es sich dabei um Belgard an der Persante handelte. Obgleich er über kein

międzywojennego, hrsg. v. R. Skrycki (Szczecin: Instytut Historii i Stosunków Międzynarodowych Uniwersytetu Szczecińskiego, 2011), 109-107; M. Dondzik, „Sztuka i ideologia - kolorowe filmy Veita Harlana z okresu III Rzeszy“, in: ebd., 87-91. Einen Überblick zum Mythos Kolberg gibt: H. J. Eitner, Kolberg. Ein preußischer Mythos 1807/1945 (Berlin: Quintessenz Verlag, 1999).

8 Zu Kolberg als Erinnerungsort siehe M. Golonka-Czajkowska, ,,Gdzie moi żołnierze, tam i ja‘. Postać Emilii Gierczak w heroicznym micie o zdobyciu Kołobrzegu“, in: Kołobrzeg i okolice poprzez wieki, hrsg. v. R. Ptaszyński (Szczecin: Kadruk, 2010), 221-244; Krasucki, „Zaślubiny z morzem“, 297-319. Vgl. auch die Konferenz zu den Mythen um Kolberg „Mity Kołobrzegu. Propaganda w służbie wojny i pokoju“, die das dortige Polnische Waffenmuseum (Muzeum Oręża Polskiego) am 18. März 2011 veranstaltete.

9 T. Tyc, „Bolesław III Krzywousty odnowiciel i wykonawca polskiej polityki północnej (1102-1138)“, in: T. Tyc, Walka o kresy zachodnie w epoce Piastów, hrsg. v. G. Labuda (Warszawa: Państwowe Zakłady Wydawnictw Szkolnych, 1948), 41, 43; T. Tyc, „Polska a Pomorze za Krzywoustego“, Roczniki Historyczne 2 (1926): 1, 27-35.

10 J. Hertel, „Pomorze w myśli politycznej elity intelektualnej wczesnośredniowiecznej Polski (Anonim Gall i Wincenty Kadłubek)“", Zapiski Historyczne 47 (1982) 4: 68-69; P. Żmudzki, Władca $i$ wojownicy. Narracja o wodzach, drużynie $i$ wojnach w najdawniejszej historiografii Polski i Rusi (Wrocław: Wydawnictwo Uniwersytetu Wrocławskiego, 2009), 199; E. Skibiński, Przemiany władzy. Narracyjna koncepcja Anonima tzw. Galla i jej podstawy (Poznań: Instytut Historii UAM, 2009), 208-209; D. Güttner-Sporzyński, Święte wojny Piastów (Warszawa: PWN, 2017), 51-75, insbesondere 70. K. Maleczyński sieht die Feldzüge Bolesław Schiefmunds zu Beginn seiner Regierungszeit als ein Unternehmen, das eines tiefer gehenden politischen Zieles entbehrte und lediglich Zbigniew in Schach halten sollte, vgl. K. Maleczyński, Bolestaw III Krzywousty (Wrocław: Ossolineum, 1975), 139-140. Demgegenüber verweisen Powierski, Śliwiński und Bruski darauf, dass die Feldzüge gegen Kolberg und Belgard den Charakter von Beutezügen hatten, vgl. J. Powierski, B. Śliwiński, K. Bruski, Studia z dziejów Pomorza w XII w. (Słupsk: Polskie Towarzystwo Historyczne, 1993), 25-26. 
größeres Heer verfügte, nahm Bolesław die Stadt im Sturm ein, plünderte sie und machte die Befestigungsanlagen dem Erdboden gleich. ${ }^{11}$ Im darauffolgenden Jahr (1103) zog Bolesław gegen die Stadt Kolberg, die ebenfalls an der Persante lag. Jedoch wurden die polnischen Krieger, als sie die Stadt stürmten, von den Reichtümern der Vorstadt derart geblendet, dass sie nicht mehr weiterkämpften. Aufgrund dieser sündhaften Verfehlung konnte Boleslaw Schiefmund trotz seines eigenen heldenhaften Einsatzes und des Heldenmuts der übrigen Kämpfer die Stadt nicht einnehmen. ${ }^{12}$ Nach Plünderung und Brandschatzung der Vorstadt mussten die Polen den Rückzug antreten. Einen positiven Effekt für die polnische Seite hatte dieser Feldzug allerdings, nämlich den, dass nun, so der Chronist, im ganzen Volksstamm der Barbaren (nacio tota barbarorum - also der Pomoranen ${ }^{13}$ ) Furcht und Schrecken herrschten vor Bolesław. ${ }^{14}$ Die Beschreibung dieses Feldzuges endet bei Gallus Anonymus mit folgendem Lied, das nach seinen eigenen Worten die Tapferkeit und den Mut der polnischen Krieger rühmen sollte:

\begin{abstract}
Pisces salsos et fetentes apportabant alii, Palpitantes et recentes nunc apportant filii.

Civitates invadebant patres nostril primitus, Hii procellas non verentur, neque maris sonitus. Agitabant patres nostro cervos, apros, capreas, Hii venantur monstra maris et opes equoreas ${ }^{15}$
\end{abstract}

11 Galli Anonymi Cronica et Gesta ducum sive principum polonorum, hrsg. v. K. Maleczyński, MPH, NS, Bd. 2 (Kraków: PAU, 1952), II, 22, S. 89.

12 Vgl. die Anmerkungen von Güttner-Sporzyński, Święte wojny, 65.

13 Die Pomoranen wurden hier als Barbaren bezeichnet. Überhaupt charakterisiert der Chronist die nördlichen Nachbarn Polens mit einer ganzen Reihe negativer Bezeichnungen wie Plünderer, Aufrührer, glitschige Frösche. All diese Epitheta und die Charakterskizzen wie die des Gniewomir sollten das Vorgehen der christlichen Polen, die die Heiden verfolgten und mit dem Schwert bekehrten, rechtfertigen. Vgl. K. Liman, „Epitety dotyczące osób w Kronice polskiej Galla Anonima“, in: Ars historica. Prace z dziejów powszechnych i Polski (Poznań: Uniwersytet im. Adama Mickiewicza, 1976), 353-355; Hertel, „Pomorze w myśli politycznej elity“, 63-65.

14 Galli Anonimi, II, 28, S. 96.

15 Galli Anonimi, II, 28, S. 97. Bemerkenswert ist, dass wir heute gleich drei polnische Übersetzungen dieses Textes haben. Sie stammen 1. von Roman Grodecki, Anonim tzw. Gall, Kronika Polska, übersetzt von R. Grodecki, bearb. v. M. Plezia (Wrocław, Warszawa, Kraków: Ossolineum, 1999) (BN I 59), 97; 2. von Ryszard Gansiniec, „Liryka Galla Anonima“, Przeglad Literacki 49 (1958) 4: 373; 3. von Stanisław Rosik, Bolesław Krzywousty (Wrocław: Chronicon, 2013), 155. Dies zeigt, wie populär dieser Text war und immer noch ist. Nach wie vor unterstreicht er die symbolische Dimension der Kämpfe der Polen um Kolberg und das Ostseeufer. Deutsche Übersetzung in: Polens Anfänge. Gallus Anonymus: Chronik und Taten der Herzöge und Fürsten von Polen, übersetzt von J. Bujnoch (Graz, Wien, Köln: Styria, 1978), 135. 
Gallus erwähnt die beiden Ortschaften erneut in seiner Beschreibung des Pommernfeldzuges im Jahre 1107. Nach Einnahme des in der Landesmitte (in medio terre ${ }^{16}$ ) gelegenen Belgard (civitas Alba) rückte der polnische Fürst zum Meer vor (ad maritima), um die dort liegende befestigte Siedlung (castrum mari proximum) Kolberg einzunehmen. Die Kolberger kamen ihm jedoch zuvor, indem sie die Stadt verließen, ihm entgegengingen und sich ergaben. Seine Dienste bot auch ein namentlich nicht bekannter Pomoranenfürst an (ipse quoque dux Pomeranorum). Bolesław zog nach der Einnahme Kolbergs fünf Wochen lang kampfeslustig durch Pommern, fand jedoch keinen Gegner, sodass er, was der Chronist hervorhebt, Pommern kampflos unterwarf. ${ }^{17}$

Spätere polnische Chroniken fassten die Berichte des Gallus Anonymus entweder zusammen oder ließen sie ganz aus. Wincenty Kadłubek erwähnt die von Gallus Anonymus beschriebenen Kämpfe Bolesław Schiefmunds gegen die Pomoranen, die dank göttlicher Hilfe zur Unterwerfung Pommerns führten. ${ }^{18} \mathrm{Er}$ greift auch die Information über das in der Landesmitte gelegene Belgard auf ${ }^{19}$ sowie über die Kolberger und die Bewohner anderer Provinzen am Meer (alie Maritimorum prouincie), die sich Boleslaw Schiefmund demütig und aus eigenem Willen ergeben hätten. ${ }^{20}$ Besondere Erwähnung verdient die Tatsache, dass Kadłubek Pommern als ,Pomorania“ oder ,Maritima“ bezeichnet, und die Pomoranen ,Pomorani` oder ,Maritimi` nennt, ${ }^{21}$ was als gebildete lateinische Übersetzung ${ }^{22}$

16 Im nächsten Satz betont der Autor, der Ort sei gleichsam das Zentrum des ganzen Landes - quasi centrum terre medium.

17 Galli Anonimi, II, 39, S. 109-110.

18 Dadurch konnte der polnische Herrscher seine Stadtthalter in Pommern ernennen und sich in einem Brief an den ungarischen König Koloman als Herrscher von Pommern bezeichnen. Vgl. Magistri Vincenti dicti Kadtubek Chronica Polonorum, hrsg. v. M. Plezia, MPH, NS, Bd. XI (Kraków: PAU, 1994), II, 24-26, S. 69-71; III, 4, S. 90-91; III, 14, S. 99-100; Hertel, „Pomorze w myśli politycznej elity“, 74-75.

19 Magistri Vincenti, III, 2, S. 88. Nach Adam Krawiec sind Lagebezeichnungen wie im Fall Belgards bei Kadłubek höchst selten und dienten der Vermittlung moralischer oder symbolischer Inhalte, der erzählerischen Gestaltung des Raumes. A. Krawiec, Ciekawość świata w średniowiecznej Polsce. Studium z dziejów geografii kreacyjnej (Poznań: Instytut Historii UAM, 2010), 266-267.

${ }^{20}$ Magistri Vincenti, III, 2, S. 89. Zur Umgestaltung der Überlieferung des Gallus Anonymus bei Kadłubek am Beispiel der Pommernkriege Bolesław Schiefmunds vgl.: D. Pandowska, „Wincentyńska transformacja kroniki Galla Anonima na przykładzie przekazu o walkach z Pomorzanami“, in: Władcy, mnisi, rycerze, hrsg. v. B. Śliwiński (Gdańsk: Wydawnictwo Uniwersytetu Gdańskiego, 1996), 81-112. Zu den Motiven, die hier von Interesse sind, vgl. ebd., 87, 93-97.

${ }_{21}$ U. a. Magistri Vincenti, II, 12, S. 41; II, 2, S. 47; III, 2, 4, S. 89, 90.

22 Pomoranen $=$ Menschen am Meer, Anm. d. Übersetzters. 
gelten darf. ${ }^{23}$ In jedem Fall aber gilt es zu bemerken, dass Kadłubek mit dem Gebrauch der Bezeichnungen ,Maritima`/Maritimi` die Botschaft bezüglich der Kämpfe und Eroberungen der Polen dahingehend verstärkt, dass polnische Krieger direkt bis ans Meeresufer vorgedrungen waren. Er tut dies zu einem Zeitpunkt, als die Zugehörigkeit Pommerns, auch des östlichen Teils, mehr und mehr zur Illusion wurde.

Der Verfasser der Großpolnischen Chronik (Kronika Wielkopolskia) schmückt den Bericht über die Belagerung Belgards aus, indem er hinzufügt, die Bewohner dieser „berühmtesten Stadt Pommerns“ hätten das Angebot, sich zu ergeben, in überheblicher Weise abgewiesen. Dennoch habe der Fürst, nachdem er die Stadt gestürmt hatte, ihnen Gnade erwiesen, das Leben geschenkt und sie vor Plünderungen bewahrt. Mit seiner Großmut, so der Chronist, habe Bolesław mehr pommersche Städte erobert als mit Waffengewalt, so hätten sich ihm unter anderem auch die Kolberger ergeben. ${ }^{24}$ Die kleinpolnische Kronika Mierzwy (Dzierzwa-Chronik) und der Kommentar des Jan z Dąbrówki ${ }^{25}$ zur Chronik des Kadłubek enthalten hingegen keine Informationen, die in unserem Zusammenhang von Interesse wären.

Die Schlesische Geschichtsschreibung behandelt das Motiv der Einnahme Kolbergs anders. Die Polnische Chronik (Kronika polska), die zwischen 1281 und 1288 im Umfeld Heinrich IV. des Gerechten entstand, enthält - verglichen mit den Berichten des Gallus Anonymus und des Kadłubek - einige interessante Details. Sie berichtet, die Kämpfer Bolesław Schiefmunds hätten sich während der Schlacht auf dem Hundsfeld mit List Zugang zum Lager des Kaisers Heinrich V. verschafft, um ihn zu entführen und in der am Meer gelegenen Stadt Kolberg ein halbes Jahr gefangen zu halten. ${ }^{26}$ Dieselbe Information findet sich in der Chronik der Fürsten Polens (Kronika książat polskich), die unter direktem Bezug auf Gallus Anonymus auch den Feldzug Bolesław Schiefmunds nach Kolberg im Jahr

23 J.M. Piskorski, Pomorze Plemienne. Historia - Archeologia - Językoznawstwo (Poznań, Szczecin: PTPN, Muzeum Narodowe w Szczecinie, 2002), 26.

${ }^{24}$ Chronica Poloniae Maioris, hrsg. v. B. Kürbis, MPH, NS, Bd. 8 (Warszawa: PWN, 1970), c. 20, S. 32 .

25 Miersuae Chronicon, MPH, Bd. II, 2. Aufl. (Warszawa: PWN, 1961); Jan z Dąbrówki, Komentarz do Kroniki polskiej Mistrza Wincentego zwanego Kadtubkiem, hrsg. v. M. Zwiercan, A.Z. Kozłowska, M. Rzepiela, MPH, NS, Bd. 14 (Kraków: PAU, 2008).

${ }^{26}$ Chronica Polonorum, hrsg. v. L. Ćwikliński, MPH, Bd. 3 (Lwów: Eigendruck, 1878), 627-628; Z. Wielgosz, „Kronika polska - metoda prezentacji dziejów“, in: Dawna historiografia ślaska. Materiaty z sesji naukowej odbytej w Brzegu w dniach 26-27 listopada 1977 (Opole: Wydawnictwo Instytutu Śląskiego w Opolu, 1980), 58-60. 
1103 erwähnt. Die Cronica Petri comitis Poloniae ${ }^{27}$ und die Cronica silesiae abbreviata $^{28}$ berichten ebenfalls über diese Vorgänge.

Die Information über den Feldzug nach Kolberg, der mit der Plünderung der Vorstadt endete, wurde direkt aus der Chronik des Gallus Anonymus in die Annalen des Jan Długosz übertragen, und zwar im Eintrag zum Jahr 1105. Der Chronist fügte allerdings einige Details hinzu, um herauszustreichen, wie schwer die Aufgabe war, denen sich die Kämpfer gegenübersahen, und um die Klugheit des polnischen Herrschers zu betonen. So vermerkt er, dass der Fluss, den es zu überqueren galt, mehr Hochwasser führte als üblich. Ein Eintrag zu Belgard findet sich unter dem Jahr 1107, wo Długosz in seinem Bericht zur Einnahme der Stadt getreu der Großpolnischen Chronik (Kronika Wielkopolska) folgt. ${ }^{29}$

Aus den oben angeführten Berichten über die beiden Ortschaften wird ersichtlich, dass sie auf besondere Weise dargestellt werden und in den Geschichtserzählungen eine besondere Funktion haben. Bereits Gallus Anonymus schrieb beiden Orten verschiedene, sich ergänzende Bedeutungen zu. Ein weiterer Aspekt ist der symbolische Reichtum Pommerns, einer der Hauptbeweggründe für die polnischen Pommernfeldzüge, ${ }^{30}$ obgleich sie bei Gallus Anonymus als wider die Heiden gerichtete Kreuzzüge dargestellt werden, als gerechte Kriege, die unter dem Schutz der Heiligen geführt wurden, insbesondere unter dem Schutz des heiligen Adalbert als Patron der polnischen Landnahme in Pommern. ${ }^{31}$

27 Chronica principium Poloniae, MPH, Bd. 3 (Lwów: Eigendruck, 1878), 457-459, 469; Cronica Petri Comitis Poloniae, MPH, NS, Bd. 3 (Kraków: PAU, 1951), 6-7.

28 Kronika Szląska Skrócona, MPH, Bd. 3 (Lwów: Eigendruck, 1878), 720.

29 Jan Długosz, Roczniki czyli kroniki sławnego Królestwa Polskiego, Buch 3-4 (Warszawa: PWN, 1969), 265-266, 274-276.

${ }^{30}$ Neben den erwarteten Reichtümern lockte vor allem die Aussicht darauf, sich im Kampf Ruhm zu erwerben, die Mannen Bolesław Schiefmunds zum Pommernfeldzug an, vgl. Galli Anonimi, II, 48, S. 118; J. Hertel, „Pomorze w myśli politycznej kronikarzy Polski piastowskiej (Anonim Gall, Wincenty Kadłubek, kronikarz wielkopolski)“, in: Prace z dziejów państwa i Zakonu Krzyżackiego, hrsg. v. A. Czacharowski (Toruń: Wydawnictwo Uniwersytetu Mikołaja Kopernika, 1984), 31; Żmudzki, Władca i wojownicy, 199.

31 J.K. Kochanowski, „Pierwotna giermanizacja Słowian pomorskich w świetle historiografii niemieckiej“, in: ders., Szkice i drobiazgi historyczne (Warszawa: Księgarnia E. Wende i Sp., 1904), 171173; Tyc, Polska a Pomorze, 30-32; G. Labuda, Święty Wojciech. Biskup-męczennik, patron Polski, Czech i Wegier (Wrocław: Wydawnictwo Uniwersytetu Wrocławskiego, 2000), 271 ff.; M. Plezia, Kronika Galla na tle historiografii XII wieku (Kraków: PAU, 1947), 61; B. Kürbis, „Pisarze i czytelnicy w Polsce XII i XIII wieku“, in: Polska dzielnicowa i zjednoczona. Państwo społeczeństwo kultura, hrsg. v. A. Gieysztor (Warszawa: PWN, 1972), 179; Hertel, „Pomorze w myśli politycznej elity“, 67-70; Hertel, „Pomorze w myśli politycznej kronikarzy“, 29-31. 
In unserem Zusammenhang ist die Lagebezeichnung für Belgard (civitas Alba) bei Gallus Anonymus als ,in der Landesmitte“ (in medio terre ${ }^{32}$ ) besonders interessant. Nach Jacek Banaszkiewicz zeugt eine solch exponierte Bezeichnung der Lage möglicherweise davon, dass sich dort ein religiöses und politisches Zentrum der Pomoranen befand. Auch die Tatsache, dass sich Bolesław Schiefmund mit seinem Heer ans Meer aufmachte (ad maritima), wo sich ihm in Kolberg ein Pomoranenfürst unterwarf, sollte auf die überregionale Bedeutung des Ortes aufmerksam machen. Die dort angehäuften Reichtümer bestätigen dies. Es ist hierbei zu beachten, dass Feldzüge gegen zentral gelegene Orte wie der des Brzetysław nach Großpolen oder unter Bolesław dem Tapferen nach Kiev, also in die Hauptstadt (caput regni), die Einnahme der für die lokale Gesellschaft bedeutenden Zentren zum Ziel hatten. Denn Herrschaft wird nicht allein durch den Herrscher repräsentiert, sondern auch durch den Ort, mit dem diese Herrschaft verbunden ist. Wer die Landesmitte besitzt, besitzt das ganze Land und trägt am Ende den Sieg davon. ${ }^{33}$ Diese Orte der Macht konnten ihrerseits zu Kristallisationspunkten für Traditionen werden. ${ }^{34}$

So wird die Einnahme beider Orte in der Erzählung des Gallus Anonymus zum Symbol der Zerstörung und Unterwerfung Pommerns bis hin zum Meer, was bereits aus dem Namen der Stadt Kołobrzeg ${ }^{35}$ - Kolberg ersichtlich wird, und somit auch zum Symbol der Unterwerfung des Landesfürsten. Dieser Akt beendete die Pommernkriege vor der Übernahme der eigenständigen Herrschaft durch Bolesław Schiefmund. ${ }^{36}$ Besondere Beachtung verdient hier der Umstand, dass Gallus Anonymus ab dem Abschnitt, in dem er von der Unterwerfung Kolbergs

32 Im nächsten Satz streicht der Autor heraus, dass dieser befestigte Ort gleichsam das Zentrum des gesamten Landes sei - quasi centrum terre medium. Vgl. auch die frühere Beschreibung Galli Anonimi, II, 22, S. 89, wo von einer hervorragenden Königsstadt (urbs regia et egregia Albam nomine) in der Mitte des heidnischen Landes (meditullium patrie paganorum) die Rede ist.

33 J. Banaszkiewicz, ,Jedność porządku przestrzennego, społecznego i tradycji początków ludu (Uwagi o urządzeniu wspólnoty plemienno-państwowej u Słowian)“, Przegląd Historyczny 77 (1986) 3: 446-449, 457-458, 464; Żmudzki, Władca i wojownicy, 199, 205.

34 P. Wiszewski, Domus Bolezlai. W poszukiwaniu tradycji dynastycznej Piastów (do około 1138 roku) (Wrocław: Wydawnictwo Uniwersytetu Wrocławskiego, 2008), 434-440.

35 Kołobrzeg = Stadt am Ufer, Anm. d. Übersetzers.

36 Z. Dalewski, Rytuat i polityka. Opowieść Galla Anonima o konflikcie Bolesława Krzywoustego ze Zbigniewem (Warszawa: Instytut Historii Nauki PAN, 2005), 98; Wiszewski, Domus Bolezlai, 302; Żmudzki, Władca $i$ wojownicy, 205; Rosik, Bolesław Krzywousty, 165-166. Nach Stanisław Rosik kann die Einahme der Königsstadt auch als Voraussage der zukünftigen Machtübernahme über das ganze Land verstanden werden. 
berichtet, Bolesław als Herzog des Nordens bezeichnet (dux vero septentriona$(i s)^{37}$, was man sicher als Eroberer des Nordens aufschlüsseln kann.

Obwohl es keine archäologischen Belege für die materielle Bedeutung Belgards gibt ${ }^{38}$, fügt sich schon der Name, der bei Gallus verwendet wird, in eine ganze Liste von Königsorten und symbolischen Zentren der damaligen Gesellschaften und Staaten ein. ${ }^{39}$ Es gilt hier zu beachten, dass zahlreiche Forscher in Kolberg-Belgard den Sitz des Fürsten über ganz Pommern bzw. einen Teil des Landes lokalisieren. ${ }^{40}$ Von der Bedeutung dieser beiden Orte zeugt auch die Tatsache, dass sie bald darauf Stationen der Missionsreise Ottos von Bamberg waren, die eigentlich dem Gebiet der Odermündung galt. ${ }^{41}$

Von der Existenz eines zentralen Ortes an der unteren Persante können wir bereits in der zweiten Hälfte des 10. Jahrhunderts ausgehen, also in der Zeit, als die Piasten ihre Herrschaft über Pommern ausdehnten. ${ }^{42}$ Dies bezeugen die Tatsache, dass dort im Jahre 1000 das Gnesen unterstellte Bistum eingerichtet wurde, sowie der Ausbau der bewehrten Siedlung in Kołobrzeg-Budzistowo (Kolberg-Altstadt), der von Archäologen mit den Piasten in Verbindung gebracht und auf das ausgehende 10. Jahrhunderts datiert wird. ${ }^{43}$ An dieser Stelle ist darauf hinzuweisen, dass vermehrt Zweifel geäußert werden daran, dass polnische Herrscher in der zweiten Hälfte des 10. Jahrhunderts und zu Beginn des 11. Jahrhunderts die Orte an der Odermündung (Stettin, Wollin) ${ }^{44}$, aus denen später Städte entstanden, ein-

37 Galli Anonimi, II, 39, S. 109-110.

38 Piskorski, Pomorze Plemienne, 176-178.

39 Vgl. J. Banaszkiewicz, ,Jedność porządku“, 463-464.

40 U. a. K. Wachowski, H. Łowmiański, W. Łosiński, J. Spors, E. Rymar, einen Überblick über die Diskussion bietet J.M. Piskorski, Pomorze Plemienne, 40 f., 58 f. Neuerdings auch bei M. Rębkowski, Chrystianizacja Pomorza Zachodniego. Studium archeologiczne (Szczecin: Instytut Archeologii i Etnologii PAN, 2007), 34; D. Wybranowski, „Jeszcze raz o taktyce wojen pomorskich Bolesława Krzywoustego oraz okolicznościach ich finału“, Przegląd Zachodniopomorski 32 (2017) 2: 72.

${ }_{4}$ S. Rosik, Conversio gentis pomeranorum. Studium świadectwa o wydarzeniu (XII wiek) (Wrocław: Chronicon, 2010), 329-337.

42 Zur Konzeption der Datierung der Einnahme Pommerns durch die Piasten siehe P. Migdalski, When did the first Polish rulers take the Pomerania? The history of certain paradigm in the Polish historiography, in: Poland, Pomerania and Their Neighbours' Shaping of Medieval European Civilisation before 1300, hrsg. v. S. Rosik, (in Druckvorbereitung).

${ }^{43}$ L. Leciejewicz, M. Rębkowski, „Uwagi końcowe. Początki Kołobrzegu w świetle rozpoznania archeologicznego", in: Kolobrzeg. Wczesne miasto nad Battykiem, hrsg. v. L. Leciejewicz, M. Rębkowski (Warszawa: Trio, 2007), 299-317; W. Łosiński, „Struktura terytorialno-polityczna Pomorza w XI stuleciu w świetle archeologii“, Slavia Antiqua 28 (1981/1982): 117.

44 Vgl. z. B. Piskorski, Pomorze Plemienne, passim; Rosik, Bolesław Krzywousty, 160. Eine andere Ansicht zum Thema Stettin vertritt Przemysław Urbańczyk, Mieszko Pierwszy Tajemniczy (Toruń: Wydawnictwo Uniwersytetu Mikołaja Kopernika, 2012), 336 ff., 365 f., 369-386. 
genommen haben sollen; auch fehlen archäologische Hinweise auf ähnliche Zentren im östlichen Pommern an der Weichselmündung. ${ }^{45}$ In dieser Situation kam den Transport- und Reisewegen zwischen den Zentren an der Persantemündung und Großpolen eine Schlüsselbedeutung zu. Sie verliefen höchstwahrscheinlich auf dem Wasserweg, und nicht unbedingt auf den Hauptströmen Oder und Weichsel, sondern über die Zuflüsse der Persante und der Drage sowie die Schleppwege in Mittelpommern. Das Bestehen eines Verkehrsweges, der durch diesen Landesteil führte, belegen die in letzter Zeit erforschten Fundorte in Nętno und am See Jezioro Zarańskie unweit von Drawsko Pomorskie (Dramburg). ${ }^{46}$ Wir hätten es also hierbei mit einem Fall zu tun, in dem die Erinnerung an einen polnischen Hof mit Hauptstadtfunktion in Kolberg und Belgard und der Unterordnung Pommerns unter Polen bereits zur Zeit der ersten Piasten erhalten wurde, ${ }^{47}$ wodurch die späteren Eroberungen durch Bolesław Schiefmund legitimiert wären.

In diesem Kontext muss das oben angeführte Lied analysiert werden. Es ist nicht nur ein kommemoratives Zeichen zum Gedenken an den Ruhm und die Tapferkeit Boleslaw Schiefmunds und seiner polnischen Krieger, wie im übrigen die gesamte Chronik, ${ }^{48}$ sondern es ist ein Manifest der polnischen Expansion in Pommern bis an die Landesgrenzen, also bis zum Meer und zu den darin verborgenen Schätzen. ${ }^{49}$ In diesem Kontext erscheint die Frage, ob es eine polnische Version dieses Liedes gab, ebenso zweitrangig wie die Frage, ob das Lied - wie Błażej Śliwiński ${ }^{50}$ annimmt - wirklich in Kolberg gesungen wurde oder - wie Marian

45 U. a. B. Śliwiński, Początki Gdańska. Dzieje ziem nad zachodnim brzegiem Zatoki Gdańskiej w I połowie X wieku (Gdańsk: Muzeum Historyczne Miasta Gdańska, 2009), passim; W. Chudziak, E. Siemianowska, „Problem przyłączenia Pomorza Środkowego do państwa pierwszych Piastów. Głos archeologa“", in: Tradycje i nowoczesność. Początki państwa polskiego na tle środkowoeuropejskim w badaniach interdyscyplinarnych, hrsg. v. H. Kóčka-Krenz, M. Matla, M. Danielewski (Poznań: Wydawnictwo Naukowe UAM, 2016), 184.

46 Chudziak, Siemianowska, „Problem przyłączenia“, 191 f.; E. Siemianowska, „O przewłokach raz jeszcze“, Studia Geohistorica. Rocznik Historyczno-Geograficzny 5 (2017): 115-139; W. Chudziak, „Wczesnośredniowieczny grot włóczni z Nętna - przyczynek do studiów nad chrystianizacją Pomorza Środkowego“, in: Świat Słowian wczesnego średniowiecza, hrsg. v. M. Dworaczyk, A. B. Kowalska, S. Moździoch, M. Rębkowski (Szczecin, Wrocław: Instytut Archeologii i Etnologii PAN, 2006), 647-655; The Island in Żótte on Lake Zarańskie. Early Medieval Gateway into West Pomerania, hrsg. v. W. Chudziak, R. Kaźmierczak (Toruń: Wydawnictwo Uniwersytetu Mikołaja Kopernika, 2014).

47 Bereits P. Wiszewski hatte darauf hingewiesen, vgl. Wiszewski, Domus Bolezlai, 438-440.

48 Ibidem, 302.

49 Vgl. die Anmerkungen von Rosik, Bolesław Krzywousty, 166-167.

50 B. Śliwiński, „Pomorze w polityce i strukturze państwa wczesnopiastowskiego (X-XII w.)“, Kwartalnik Historyczny 107 (2000) 2: 31, 108. 
Plezia meint - es sich um eine literarische Fiktion des Gallus Anonymus handelt, die für die Chronik direkt in lateinischer Sprache verfasst wurde. ${ }^{51}$

Wenn der Bericht des Gallus Anonymus eine klar umrissene symbolische Funktion hatte, muss man überlegen, welchen potentiellen Wirkungskreis er haben konnte. In Frage kommt hier nur die Elite, also lesekundige Geistliche und Laien, die am Hof des Fürsten Zugang zur Chronik des Gallus Anonymus hatten. ${ }^{52}$ Der Umstand, dass der Chronist gebundene Prosa, Reime und Rhythmen verwendet, sodass das Werk auch vor einem ausgewählten Publikum rezitiert und in Teilen sogar gesungen ${ }^{53}$ werden konnte, trug nicht wesentlich zu seiner Verbreitung bei. ${ }^{54}$

Aufgrund dieser Einschränkungen konnte die Darstellung des Gallus Anonymus nicht in das kollektive Bewusstsein eingehen, auch nicht in das der damals zahlenmäßig kleinen Elite. Wir können daher nur feststellen, dass es sich im Fall des Berichts über Belgard und Kolberg um den Versuch handelte, einen politischen Mythos zu erschaffen, der Handlungsmuster vorgab. ${ }^{55}$ Im Übrigen verlor dieses erzählerische Konstrukt schnell an Bedeutung. Die Bedeutungsdekonstruktion setzte ein, was nicht nur mit dem Verstummen des Verfassers (um 1118) und dem Ende der Kämpfe um Pommern (um 1122/1123) zu tun hatte, sondern

51 M. Plezia, „Wstęp“, in: Anonim tzw. Gall, Kronika Polska, übers. v. R. Grodecki, bearb. v. M. Plezia (Wrocław, Warszawa, Kraków: Ossolineum, 1999), XLIX; Gansiniec, Liryka, 356-357. Selbst wenn man davon ausgeht, dass das Werk - wie in der damaligen Kultur üblich - bereits zuvor in mündlicher Form überliefert worden war, so wurde es, wie Skibiński darlegt, aus wichtigen politischen Gründen überformt und in der Chronik in lateinischer Sprache aufgeschrieben und damit festgehalten. Vgl. Skibiński, Przemiany władzy, 28.

52 B. Geremek, „Wyobraźnia czasowa polskiego dziejopisarstwa średniowiecznego“, Studia Źródłoznawcze 22 (1977): 3; Wiszewski, Domus Bolezlai, 19.

53 B. Kürbis, „Pisarze i czytelnicy“, 177.

54 Nach E. Skibiński war „Polen im 12. Jahrhundert ein Land mit überwiegend mündlicher Kultur. Die lateinischen Autoren waren aber für einen Kreis von Lesern lateinischer Texte tätig und somit müssen wir sie zu einer Gruppierung zählen, die sich der Schrift bediente“ (E. Skibiński, „Elementy kultury oralnej w kronikach Galla Anonima i Wincentego Kadłubka“, Res Historica 3 (1998): 64). Vgl. die Anmerkungen von P. Węcowski, Początki Polski w pamięci historycznej późnego średniowiecza (Kraków: Societas Vistulana, 2014), 19. Über die Beziehung von Sender und Empfänger in der Chronik des Gallus Anonymus siehe: W. Polak, „Gesta Gallowe a kultura oralna“, in: Tekst źródta. Krytyka. Interpretacja, hrsg. v. B. Trelińska (Warszawa: DiG, 2005), 72-75.

55 Ausführlicher zum Mythos: A. von Saldern, „Mythen, Legenden und Stereotypen“, in: Mythen in Geschichte und Geschichtsschreibung aus polnischer und deutsche Sicht, hrsg. v. A. von Saldern (Münster: LIT, 1996), 14-17; S. Filipowicz, Mit i spektakl władzy (Warszawa: PWN, 1988), 42-45, 53-54. Eine ähnliche Definition bei M. Eliade, Traktat o historii religii (Warszawa: Książka i Wiedza, 1966), 403-427, insbesondere: 404-410, 419, 423; M. Eliade, Mity, sny i misteria (Warszawa: Wydawnictwo KR, 1994), 7-8. Auf die zyklische Erscheinungsform einiger früherer Rituale verweist auch E. Cassirer, Mit państwa, übers. v. A. Staniewska (Warszawa: IFiS PAN, 2006), 310. 
vor allem damit, dass Bolesław Schiefmund spätestens nach der endgültigen Eroberung Pommerns das politische Zentrum des Landes an die Odermündung (Stettin, Wollin, Cammin, Usedom) verlegte sowie damit, dass seine Nachfolger keine aktive Nordpolitik betrieben. Die einzige Verbindung zwischen den Piasten und den pommerschen Herzögen kamen durch von Mieszko III. betriebene Heiraten zustande (wofür ihn seinerzeit der Chronist Wincenty Kadłubek lobte) sowie durch die heutzutage zunehmend rätselhaft erscheinende Unterstellung des pommerschen Bistums in Wollin unter das Erzbistum Gnesen. ${ }^{56}$

Parallel dazu erlebten die erwähnten Erzählmotive zu Kolberg und Belgard im 13. Jahrhundert aufgrund der neuen politischen Situation - Pommern war nun von Polen unabhängig - bedeutende Veränderungen. Im 13. Jahrhundert gaben schlesische Chronisten Kolberg als einen Ort an, in dem der während seines Polenfeldzuges 1109 in Gefangenschaft geratene deutsche König Heinrich V. festgehalten wurde. ${ }^{57}$ Durch die Nennung Kolbergs sollte scheinbar die Randlage des Ortes, an dem Heinrich festgehalten wurde, unterstrichen werden. Es handelte sich zwar um eine wichtige und stark befestigte Anlage, die jedoch an der Peripherie lag und über die man so gut wie nichts wusste, obwohl polnische und auch schlesische Kirchenstellen dort Güter besaßen. ${ }^{58}$ Dadurch sollte die gesamte Erzählung an Glaubhaftigkeit gewinnen. Die Geschichte der Schlacht von Hundsfeld und der Gefangennahme Heinrichs taucht erstmals in der schlesischen Polnischen Chronik (Kronika polska) auf und fügte sich gut in den breiteren Kontext dieses Werkes, das Polen als ein Land darstellte, das seit Jahrhunderten mit dem Kaiserreich verbunden war, während die Polen selbst die Deutschen hassten und im Kampf vor List und Hinterhalten nicht zurückschreckten. ${ }^{59}$

Das Motiv der Kämpfe um Kolberg und Belgard lebte, wenn auch in abgeschwächter Form, in den Annalen des Jan Długosz wieder auf. Dies ist kein Zufall,

${ }_{56}$ Magistri Vincenti, IV, 2, S. 130-131; 12, S. 152; Hertel, „Pomorze w myśli politycznej elity“, 75-77; Hertel, „Pomorze w myśli politycznej kronikarzy“, 35-36; zum pommerschen Bistum im 12. Jahrhundert neuerdings bei P. Piątkowski, Biskupstwo pomorskie jako początek biskupstwa kamieńskiego (Wrocław: Chronicon, 2015).

57 Dies stützt die These B. Geremeks, der zufolge Ereignisse in der Beschreibung mit wachsendem zeitlichem Abstand zunehmend mit legendenähnlichen Motiven ausgeschmückt werden. Vgl.: Geremek, „Wyobraźnia czasowa“, 8.

58 Ich denke hier an die Verleihung einer der Kolberger Salinen an das Zisterzienserinnenkloster in Trebnitz (Trzebnica) im Jahre 1214 (Pommersches Urkundenbuch, Bd. I, hrsg. v. K. Conrad (Köln, Wien: Böhlau, 1970), Nr. 162 und an die Einflüsse des Klosters in Mogilno (siehe J. Petersohn, Der südliche Ostseeraum im kirchlich-politischen Kräftespiel der Reichs, Polens und Dänemarks vom 10. bis 13. Jahrhundert (Köln, Wien: Böhlau, 1979), 424 f.).

59 Wielgosz, „Kronika polska“, 54, 58-60. 
denn Pommern spielte bei Długosz eine wichtige Rolle. Er forderte sogar, ein Teil Pommerns müsse wieder zu Polen kommen als Bestandteil der alten lechischen Gebiete, die dann unter die Herrschaft Bolesław des Tapferen gekommen waren. ${ }^{60}$

Ich möchte meine Überlegungen mit dem Hinweis darauf abschließen, dass man aufgrund der dargelegten Analyse sagen kann, dass bereits im 12. Jahrhundert, zur Zeit der Pommernzüge Bolesław Schiefmunds, im Umkreis seines Hofes und seines Chronisten Gallus Anonymus der Versuch unternommen wurde, den beiden mittelpommerschen Hauptorten Kolberg und Belgard eine symbolische Bedeutung zuzuschreiben. Sie standen symbolisch für die polnische Herrschaft über Gebiete in Pommern. Da diese Geschichtserzählung, die Züge eines politischen Mythos trägt, nur kurze Zeit aktuell war, bildete sich kein kollektives Bewusstsein um diese Erzählung heraus. Ein solches wäre (nach B. Geremek, der darin M. Halbwachs folgt) politisch organisiert und würde ein integratives Moment einer bestimmten herrschernahen gesellschaftlichen Gruppe darstellen. Im Mittelalter belegte sie, wie Geremek dargelegt hat, vor allem die herausragende Rolle des Christentums und legitimierte die Herrschaft. ${ }^{61}$ In späteren Werken unterlag die symbolische Bedeutung dieser Erzählung einem Wandel, indem sie (so in Schlesien) mit dem aktuellen politischen Diskurs verwoben wurde. Die Erzählmotive der Kämpfe um diese Orte wurden nur dann aufgegriffen, wenn die Idee einer Verbindung zwischen Pommern und Polen wiederauflebte, was am Beispiel der Großpolnischen Chronik, bei Długosz und insbesondere nach 1945 deutlich wird.

Übersetzung: Torsten Salzer

${ }^{60}$ „Ich wäre glücklich, wenn vor meinen Augen nach der Güte des Herrn Schlesien, das Lebuser und Stolper Land, wo sich drei Bistümer befinden, die gegründet wurden von dem ersten König Polen, Bolesław dem Großen und dessen Vater Mieczysław, zum Polnischen Königreich zuückkämen und mit ihm vereinigt würden" (Joanis Dlugossii seu Longini Canonici Cracoviensis Historiae Poloniae libri XII), hrsg. v. A. Przeździecki, Bd. 5, liber XII (XIII) (Cracovie: Typographia Kirchmayerana, 1878), 473, übers. v. Torsten Salzer nach: J. Długosz, Roczniki czyli kroniki sławnego Królestwa Polskiego, Ks. 12 1462-1480 (Warszawa: PWN, 2006), 186; Vgl. Anm. von J. Krzyżaniakowa, „Pojęcie narodu w ,Rocznikach“ Jana Długosza“, in: Sztuka i ideologia XV wieku, hrsg. v. P. Skubiszewski (Warszawa: PWN, 1978), 143, 145; S. Gawlas, „Świadomość narodowa Jana Długosza“, Studia Źródtoznawcze 27 (1983): 41 sowie S. Gawęda, K. Pieradzka, J. Radziszewska, Rozbiór krytyczny Annalium Poloniae Jana Dlugosza z lat 1445-1480, Bd. 2 (Wrocław: Ossolineum, 1965), 210.

${ }^{61}$ Geremek, „Wyobraźnia czasowa“, 15. 


\section{Bibliografie}

\section{Quellen}

Anonim tzw. Gall. Kronika Polska. Przeł. R. Grodecki, opr. M. Plezia. Wrocław, Warszawa, Kraków: Ossolineum, 1999 (BN I 59).

Chronica Poloniae Maioris, hrsg. v. B. Kürbis, MPH, NS, Bd. 8. Warszawa: PWN, 1970.

Chronica Polonorum, ed. L. Ćwikliński, MPH, Bd. 3. Lwów: Eigendruck, 1878.

Chronica principium Poloniae, MPH, Bd. 3. Lwów: Eigendruck, 1878.

Cronica Petri Comitis Poloniae, MPH, NS, Bd. 3. Kraków: PAU, 1951.

Długosz, J. Roczniki czyli kroniki sławnego Królestwa Polskiego, ks. 3-4. Warszawa: PWN, 1969.

Długosz, J. Roczniki czyli kroniki sławnego Królestwa Polskiego, Buch 12, 1462-1480. Warszawa: PWN, 2006.

Galli Anonymi Cronica et Gesta ducum sive principum polonorum, hrsg. v. K. Maleczyński, MPH, NS, Bd. 2. Kraków: PAU, 1952.

Jan z Dąbrówki. Komentarz do Kroniki polskiej Mistrza Wincentego zwanego Kadtubkiem, hrsg. v. M. Zwiercan, mit A.Z. Kozłowska, M. Rzepiela, MPH, NS, Bd. 14. Kraków: PAU, 2008.

Joanis Dtugossii seu Longini Canonici Cracoviensis Historiae Poloniae libri XII, hrsg. v. A. Przeździecki, Bd. 5, liber XII (XIII). Cracovie: Typographia Kirchmayerana, 1878.

Kronika Szląska Skrócona. MPH, Bd. 3. Lwów 1878.

Magistri Vincenti dicti Kadtubek Chronica Polonorum, hrsg. v. M. Plezia, MPH, NS, Bd. I. Kraków: PAU, 1994.

Miersuae Chronicon. MPH, Bd. II, 2. Aufl. Warszawa: PWN, 1961.

Polens Anfänge. Gallus Anonymus: Chronik und Taten der Herzöge und Fürsten von Polen. Übers. v. J. Bujnoch. Graz, Wien, Köln: Styria, 1978.

Pommersches Urkundenbuch, Bd. I, hrsg. v. K. Conrad. Köln, Wien: Böhlau, 1970.

\section{Literatur}

Banaszkiewicz, J. „Jedność porządku przestrzennego, społecznego i tradycji początków ludu (Uwagi o urządzeniu wspólnoty plemienno-państwowej u Słowian)“. Przegląd Historyczny 77 (1986) 3: 445-466. 
Bastowska, K. „Polityka władz wobec zabytkowych obiektów sakralnych Pomorza Środkowego w latach 1945-1966 - mity, niedomówienia, półprawdy“. In: Kościół katolicki $w$ realiach władzy komunistycznej na Pomorzu Środkowym w latach 1945 1989, hrsg. v. P. Knap, T. Ceynowa, 71-102. Szczecin: IPN, 2011.

Bittner, K. Piosenka w stużbie propagandy. Festiwal Piosenki Żołnierskiej w Kołobrzegu 1968-1989. Poznań: IPN, 2015.

Cassirer, E. Mit państwa. Übers. v. A. Staniewska. Warszawa: IFiS PAN, 2006.

Chudziak, W., E. Siemianowska. „Problem przyłączenia Pomorza Środkowego do państwa pierwszych Piastów. Głos archeologa“. In: Tradycje i nowoczesność. Początki państwa polskiego na tle środkowoeuropejskim w badaniach interdyscyplinarnych, hrsg. v. H. Kóčka-Krenz, M. Matla, M. Danielewski, 181-200. Poznań: Wydawnictwo Naukowe UAM, 2016.

Chudziak, W. „Wczesnośredniowieczny grot włóczni z Nętna - przyczynek do studiów nad chrystianizacją Pomorza Środkowego“. In: Świat Słowian wczesnego średniowiecza, hrsg. v. M. Dworaczyk, A.B. Kowalska, S. Moździoch, M. Rębkowski, 647-655. Szczecin, Wrocław: Instytut Archeologii i Etnologii PAN, 2006.

Dalewski, Z. Rytuat i polityka. Opowieść Galla Anonima o konflikcie Bolesława Krzywoustego ze Zbigniewem. Warszawa: Instytut Historii Nauki PAN, 2005.

Dondzik, M. „Sztuka i ideologia - kolorowe filmy Veita Harlana z okresu III Rzeszy“. In: Konstelacja Szczecin. Aktorzy szczecińscy i kino okresu międzywojennego, hrsg. v. R. Skrycki, 73-91. Szczecin: Instytut Historii i Stosunków Międzynarodowych Uniwersytetu Szczecińskiego, 2011.

Dopierała, B. Polskie losy Pomorza Zachodniego. Poznań: Wydawnictwo Poznańskie, 1970.

Eitner, H.-J. Kolberg. Ein preußischer Mythos 1807/1945. Berlin: Quintessenz Verlag, 1999.

Eliade, M. Mity, sny i misteria. Warszawa: Wydawnictwo KR, 1994.

Eliade, M. Traktat o historii religii. Warszawa: Książka i Wiedza, 1966.

Filipowicz, S. Mit i spektakl władzy. Warszawa: PWN, 1988.

Gansiniec, R. „Liryka Galla Anonima“. Przegląd Literacki 49 (1958) 4: 355-387.

Gawęda, S., K. Pieradzka, J. Radziszewska. Rozbiór krytyczny Annalium Poloniae Jana Długosza z lat 1445-1480, Bd. 2. Wrocław: Ossolineum, 1965.

Gawlas, S. „Świadomość narodowa Jana Długosza“. Studia Źródłoznawcze 27 (1983): 3-66.

Geremek, B. „Wyobraźnia czasowa polskiego dziejopisarstwa średniowiecznego“. Studia Źródłoznawcze 22 (1977): 1-17. 
Golonka-Czajkowska, M. „,Gdzie moi żołnierze, tam i ja‘. Postać Emilii Gierczak w heroicznym micie o zdobyciu Kołobrzegu“. In: Kołobrzeg i okolice poprzez wieki, hrsg. v. R. Ptaszyński, 221-244. Szczecin: Kadruk, 2010.

Grabski, A. F. Bolesław Krzywousty 1085-1138. Warszawa: Ministerstwo Obrony Narodowej, 1968.

Gustowski, L. Polska a Pomorze Odrzańskie. Warszawa: Państwowe Zakłady Wydawnictw Szkolnych, 1946.

Güttner-Sporzyński, D. Święte wojny Piastów. Warszawa: PWN, 2017.

Hertel, J. „Pomorze w myśli politycznej elity intelektualnej wczesnośredniowiecznej Polski (Anonim Gall i Wincenty Kadłubek)“. Zapiski Historyczne 47 (1982) 4: 53-80.

Hertel, J. „Pomorze w myśli politycznej kronikarzy Polski piastowskiej (Anonim Gall, Wincenty Kadłubek, kronikarz wielkopolski)“. In: Prace z dziejów państwa i Zakonu Krzyżackiego, hrsg. v. A. Czacharowski, 9-47. Toruń: Wydawnictwo Uniwersytetu Mikołaja Kopernika, 1984.

Kochanowski, J.K. „Pierwotna giermanizacja Słowian pomorskich w świetle historiografii niemieckiej“. In: J.K. Kochanowski. Szkice i drobiazgi historyczne. Warszawa: Księgarnia E. Wende i Sp., 1904.

Krasucki, E. „Zaślubiny z morzem - powojenny mit założycielski Kołobrzegu. Kilka uwag wokół nieco wstydliwej historii“. In: Kołobrzeg i okolice poprzez wieki, hrsg. v. R. Ptaszyński, 297-319. Szczecin: Kadruk, 2010.

Krawiec, A. Ciekawość świata w średniowiecznej Polsce. Studium z dziejów geografii kreacyjnej. Poznań: Instytut Historii UAM, 2010.

Kroczyński, H. Zaślubiny Polski z morzem. Kołobrzeg: Le Petit Café, 1999.

Krzyżaniakowa, J. „Pojęcie narodu w ,Rocznikach“ Jana Długosza“. In: Sztuka i ideologia XV wieku, hrsg. v. P. Skubiszewski, 135-153. Warszawa: PWN, 1978.

Kürbis, B. „Pisarze i czytelnicy w Polsce XII i XIII wieku“. In: Polska dzielnicowa i zjednoczona. Państwo społeczeństwo kultura, hrsg. v. A. Gieysztor, 159-201. Warszawa: PWN, 1972.

Labuda, G. Historia Kaszubów w dziejach Pomorza. Bd. I: Czasy średniowieczne. Gdańsk: Instytut Kaszubski, 2006.

Labuda, G. Święty Wojciech. Biskup-męczennik, patron Polski, Czech i Węgier. Wrocław: Wydawnictwo Uniwersytetu Wrocławskiego, 2000.

Leciejewicz, L., M. Rębkowski. „Uwagi końcowe. Początki Kołobrzegu w świetle rozpoznania archeologicznego“. In: Kołobrzeg. Wczesne miasto nad Battykiem, hrsg. v. L. Leciejewicz, M. Rębkowski, 299-317. Warszawa: Trio, 2007. 
Liman, K. „Epitety dotyczące osób w Kronice polskiej Galla Anonima““. In: Ars historica. Prace z dziejów powszechnych i Polski, 341-355. Poznań: Uniwersytet im. Adama Mickiewicza, 1976.

Łosiński, W. „Struktura terytorialno-polityczna Pomorza w XI stuleciu w świetle archeologii“. Slavia Antiqua 28 (1981/1982): 113-124.

Maleczyński, K. Bolesław III Krzywousty. Wrocław: Ossolineum, 1975.

Mazur, Z. „Między ratuszem, kościołem i cmentarzem“. In: Wokót niemieckiego dziedzictwa kulturowego na Ziemiach Zachodnich i Pótnocnych, hrsg. v. Z. Mazur, 301-340. Poznań: Instytut Zachodni, 1997.

Migdalski, P. When did the first Polish rulers take the Pomerania? The history of certain paradigm in the Polish historiography, in: Poland, Pomerania and Their Neighbours' Shaping of Medieval European Civilisation before 1300, hrsg. v. S. Rosik, (in Druckvorbereitung).

Migdalski, P. „Kreowanie polityki pamięci w Wolinie w okresie kulminacji obchodów Tysiąclecia Państwa Polskiego (1966-1967)“. In: Kulturowe konteksty pamięci Pomorzan. XIII Konferencja Kaszubsko-Pomorska, hrsg. v. C. Obracht-Prądzyński, 156-179. Słupsk, Gdańsk: Muzeum Pomorza Środkowego, 2016.

Mitkowski, J. Pomorze Zachodnie w stosunku do Polski. Poznań: Instytut Zachodni, 1946.

Myślenicki, W. Piastowski nurt Odry. Poznań: Wydawnictwo Poznańskie, 1972.

Pandowska, D. „Wincentyńska transformacja kroniki Galla Anonima na przykładzie przekazu o walkach z Pomorzanami“. In: Władcy, mnisi, rycerze, hrsg. v. B. Śliwiński. 81-112. Gdańsk: Wydawnictwo Uniwersytetu Gdańskiego, 1996.

Petersohn, J. Der südliche Ostseeraum im kirchlich-politischen Kräftespiel der Reichs, Polens und Dänemarks vom 10. bis 13. Jahrhundert. Köln, Wien: Böhlau, 1979.

Piątkowski, P. Biskupstwo pomorskie jako początek biskupstwa kamieńskiego. Wrocław: Chronicon, 2015.

Piskorski, J. M. Pomorze Plemienne. Historia - Archeologia-Językoznawstwo. Poznań, Szczecin: PTPN-Muzeum Narodowe w Szczecinie, 2002.

Plezia, M. Kronika Galla na tle historiografii XII wieku. Kraków: PAU, 1947.

Plezia, M. „Wstęp“. In: Anonim tzw. Gall, Kronika Polska. Übers. v. R. Grodecki, bearb. v. M. Plezia, III-LXXXI. Wrocław, Warszawa, Kraków: Ossolineum, 1999.

Polak, W. „Gesta Gallowe a kultura oralna“. In: Tekst źródła. Krytyka. Interpretacja, hrsg. v. B. Trelińska, 65-76. Warszawa: DiG, 2005.

Powierski, J., B. Śliwiński, K. Bruski. Studia z dziejów Pomorza w XII w. Słupsk: Polskie Towarzystwo Historyczne, 1993. 
Prusak, M. „Obraz walk o Kołobrzeg w 1945 roku w audycjach Radia Koszalin w latach 1953-1989“. In: Polifonia pamięci. Między niemiecka przeszłościa a polska teraźniejszościa. Kołobrzeg 1945-2015, hrsg. v. R. Ptaszyński, J. Suchy, 183-204. Szczecin: Wydawnictwo Naukowe Wydziału Humanistycznego Uniwersytetu Szczecińskiego MINERWA, 2017.

Rębkowski, M. Chrystianizacja Pomorza Zachodniego. Studium archeologiczne. Szczecin: Instytut Archeologii i Etnologii PAN, 2007.

Romanow, Z. Kreowanie ,polityki pamięci“ na Pomorzu Zachodnim w latach 1945-2000. Poznań: Instytut Zachodni, 2002 (Zeszyty Instytutu Zachodniego Nr 24/2002).

Rosik, S. Bolesław Krzywousty. Wrocław: Chronicon, 2013.

Rosik, S. Conversio gentis pomeranorum. Studium świadectwa o wydarzeniu (XII wiek). Wrocław: Chronicon, 2010.

Rosik, S. „Reinbern - Salse Cholbergiensis aecclesice episcopus“. In: Salsa Cholbergiensis. Kołobrzeg w średniowieczu, hrsg. v. L. Leciejewicz, M. Rębkowski, 85-93. Kołobrzeg: Le Petit Café, 2000.

Saldern A. von. „Mythen, Legenden und Stereotypen“. In: Mythen in Geschichte und Geschichtsschreibung aus polnischer und deutscher Sicht, hrsg. v. A. von Saldern, 13-26. Münster: LIT, 1996.

Schich, W. Wirtschaft und Kulturlandschaft. Gesammelte Beiträge 1977 bis 1999 zur Geschichte der Zisterzienser und der „Germania Slavica“. Berlin: BWV - Berliner Wissenschafts-Verlag, 2007.

Schröder, U. „Veit Harlans ,Kolberg‘. Der letzte ,Großfilm“ der UFA“. In: Konstelacja Szczecin. Aktorzy szczecińscy i kino okresu międzywojennego, hrsg. v. R. Skrycki, 109-115. Szczecin: Instytut Historii i Stosunków Międzynarodowych Uniwersytetu Szczecińskiego, 2011.

Siemianowska, E. „O przewłokach raz jeszcze“. Studia Geohistorica. Rocznik Historyczno-Geograficzny 5 (2017): 115-139.

Skibiński, E. „Elementy kultury oralnej w kronikach Galla Anonima i Wincentego Kadłubka“. Res Historica 3 (1998): 63-72.

Skibiński, E. Przemiany władzy. Narracyjna koncepcja Anonima tzw. Galla i jej podstawy. Poznań: Instytut Historii UAM, 2009.

Śliwiński, B. Początki Gdańska. Dzieje ziem nad zachodnim brzegiem Zatoki Gdańskiej w I połowie X wieku. Gdańsk: Muzeum Historyczne Miasta Gdańska, 2009.

Śliwiński, B. „Pomorze w polityce i strukturze państwa wczesnopiastowskiego (XXII w.)“. Kwartalnik Historyczny 107 (2000) 2: 3-40. 
The Island in Żólte on Lake Zarańskie. Early Medieval Gateway into West Pomerania, hrsg. v. W. Chudziak, R. Kaźmierczak. Toruń: Wydawnictwo Uniwersytetu Mikołaja Kopernika, 2014.

Tyc, T. „Bolesław III Krzywousty odnowiciel i wykonawca polskiej polityki północnej (1102-1138)“. In: T. Tyc. Walka o kresy zachodnie w epoce Piastów, hrsg. v. G. Labuda, 39-64. Warszawa: Państwowe Zakłady Wydawnictw Szkolnych, 1948.

Tyc, T. „Polska a Pomorze za Krzywoustego“. Roczniki Historyczne 2 (1926): 1-36.

Urbańczyk, P. Mieszko Pierwszy Tajemniczy. Toruń: Wydawnictwo Uniwersytetu Mikołaja Kopernika, 2012.

Watrak, J., A. Sawicka. „Die polnische Lyrik nach 1945 über Kołobrzeg (Kolberg). Einige Anmerkungen“. Pommersches Jahrbuch für Literatur 2 (2007): 274-299.

Węcowski, P. Początki Polski w pamięci historycznej późnego średniowiecza. Kraków: Societas Vistulana, 2014.

Wielgosz, Z. „Kronika polska - metoda prezentacji dziejów“. In: Dawna historiografia ślaska. Materiaty z sesji naukowej odbytej w Brzegu w dniach 26-27 listopada 1977, 44-60. Opole: Wydawnictwo Instytutu Śląskiego w Opolu, 1980.

Wiszewski, P. Domus Bolezlai. W poszukiwaniu tradycji dynastycznej Piastów (do około 1138 roku). Wrocław: Wydawnictwo Uniwersytetu Wrocławskiego, 2008.

Wybranowski, D. „Jeszcze raz o taktyce wojen pomorskich Bolesława Krzywoustego oraz okolicznościach ich finału“. Przeglad Zachodniopomorski 32 (2017) 2: 67-111.

Żmudzki, P. Władca $i$ wojownicy. Narracja o wodzach, drużynie $i$ wojnach w najdawniejszej historiografii Polski i Rusi. Wrocław: Wydawnictwo Uniwersytetu Wrocławskiego, 2009.

\title{
WYPRAWY BOLESLAWA KRZYWOUSTEGO NA BIALOGARD ORAZ KOLOBRZEG I POCZĄTKI POLSKIEGO SYMBOLICZNEGO ZAWLASZCZANIA POMORZA ORAZ WALK O DOSTĘP DO BALTYKU
}

Słowa kluczowe: historia Polski, historia Pomorza, polskie kroniki średniowieczne, mity historyczne, Kołobrzeg, Białogard

\begin{abstract}
Abstrakt
Kołobrzeg był przez prawie 150 lat ważnym miejscem pamięci w Niemczech. W 1945 roku teren Pomorza wraz z tym nadmorskim miastem objęło, po krwawych walkach
\end{abstract}


armii polskiej, państwo polskie. Nawiązując do walk z 1945 roku, Polacy utworzyli wiele mitów historycznych odwołujących się również do narracji średniowiecznych. Celem artykułu jest próba zbadania na podstawie przekazów kronikarskich, czy już w okresie średniowiecza narracja o Kołobrzegu i pobliskim Białogardzie nie zaczęła spełniać podobnej roli w polityce symbolicznej wśród polskich elit. W pierwszej części artykułu omówiono przekazy dziejopisów o wyprawach Bolesława Krzywoustego na Białogard oraz Kołobrzeg. W drugiej zaś omówiono ich znaczenie na tle ówczesnej sytuacji politycznej. Wydaje się, że w początkach XII wieku Gall Anonim próbował nadać symboliczne znaczenie obu tym ośrodkom, jednak z czasem kronikarze zmienili pierwotny sens tego przekazu i wplatali jego elementy w aktualny dyskurs polityczny. Wątki te powracały jedynie wtedy, kiedy odżywała idea łączności Pomorza z Polską. 